\title{
Landmark Data to Distinguish and Identify Morphologically Close Tabanus spp. (Diptera: Tabanidae)
}

\author{
Tanasak Changbunjong ${ }^{1,2, *(D)}$, Nutnicha Prakaikowit ${ }^{1}$, Photchanun Maneephan ${ }^{1}$, Tipparat Kaewwiset ${ }^{1}$, \\ Thekhawet Weluwanarak ${ }^{2}$, Tanawat Chaiphongpachara ${ }^{3}$ and Jean-Pierre Dujardin ${ }^{4}$ \\ 1 Department of Pre-Clinic and Applied Animal Science, Faculty of Veterinary Science, Mahidol University, \\ Nakhon Pathom 73170, Thailand; nutnicha.pra@student.mahidol.edu (N.P.); \\ photchanun.man@student.mahidol.edu (P.M.); tipparat.kea@student.mahidol.edu (T.K.) \\ 2 The Monitoring and Surveillance Center for Zoonotic Diseases in Wildlife and Exotic Animals (MoZWE), \\ Faculty of Veterinary Science, Mahidol University, Nakhon Pathom 73170, Thailand; \\ thekhawet.wel@mahidol.edu \\ 3 Department of Public Health and Health Promotion, College of Allied Health Science, Suan Sunandha \\ Rajabhat University, Samut Songkhram 75000, Thailand; tanawat.ch@ssru.ac.th \\ 4 Institut de Recherche pour le Développement (IRD), Unité Mixte de Recherches INTERTRYP (IRD, \\ et Centre de Coopération Internationale en Recherche Agronomique pour le Développement, CIRAD), \\ University of Montpellier, F-34398 Montpellier, France; dujjepi@gmail.com \\ * Correspondence: tanasak.cha@mahidol.edu
}

check for updates

Citation: Changbunjong, T; Prakaikowit, N.; Maneephan, P.; Kaewwiset, T.; Weluwanarak, T.; Chaiphongpachara, T.; Dujardin, J.-P. Landmark Data to Distinguish and Identify Morphologically Close Tabanus spp. (Diptera: Tabanidae). Insects 2021, 12, 974. https://doi.org/ $10.3390 /$ insects 12110974

Academic Editor: John O. Stireman III

Received: 30 August 2021

Accepted: 23 October 2021

Published: 28 October 2021

Publisher's Note: MDPI stays neutral with regard to jurisdictional claims in published maps and institutional affiliations.

Copyright: (c) 2021 by the authors. Licensee MDPI, Basel, Switzerland. This article is an open access article distributed under the terms and conditions of the Creative Commons Attribution (CC BY) license (https:/ / creativecommons.org/licenses/by/ $4.0 /)$.
Simple Summary: Tabanus spp. (Diptera: Tabanidae) are blood-sucking parasites of animals and humans. The accurate identification of these flies is very important for determining the vector species involved in disease transmission and for planning effective vector control and management strategies. We explored the effectiveness of landmark-based geometrics at distinguishing and identifying morphologically similar species of Tabanus (T. megalops, T. rubidus, and T. striatus) in Thailand. Our study reveals that geometric morphometrics is effective at distinguishing between the three species of Tabanus. Furthermore, our study material can be used as reference material for species identification.

Abstract: Tabanus spp., also known as horse flies (Diptera: Tabanidae), are important vectors of several animal pathogens. Adult females of Tabanus megalops and Tabanus striatus, which are members of the T. striatus complex, are morphologically similar and hence difficult to distinguish using morphological characteristics. In addition, molecular identification by DNA barcoding is also unable to distinguish these species. These two species can occur sympatrically with Tabanus rubidus, which is morphologically similar to T. megalops and T. striatus. Wing geometric morphometrics has been widely used in various insects to distinguish morphologically similar species. This study explored the effectiveness of landmark-based geometrics at distinguishing and identifying T. megalops, T. rubidus, and T. striatus in Thailand. Specimens were collected from different geographical regions of Thailand, and only unambiguously identified specimens were used for geometric morphometric analyses. Left wings of females of T. megalops $(\mathrm{n}=160)$, T. rubidus $(\mathrm{n}=165)$, and T. striatus $(\mathrm{n}=85)$ were photographed, and 22 wing landmarks were used for the analysis. Wing shape was able to distinguish among species with high accuracy scores, ranging from $94.38 \%$ to $99.39 \%$. We showed that morphologically very close species of Tabanus can be reliably distinguished by the geometry of their wing venation, and we showed how our experimental material could be used as a reference to tentatively identify new field collected specimens.

Keywords: geometric morphometrics; horse flies; Tabanus megalops; Tabanus rubidus; Tabanus striatus; vector 


\section{Introduction}

Tabanus spp., also known as horse flies (Diptera: Tabanidae), are hematophagous flies of medical and veterinary importance. They are classified into the suborder Brachycera, the infraorder Tabanomorpha, and the family Tabanidae. Approximately 1300 species have been described [1]. Female flies feed on pets, livestock, wildlife, and occasionally, humans. They are biological vectors of Trypanosoma theileri, and mechanical vectors of other trypanosomes, such as Trypanosoma brucei, Trypanosoma congolense, Trypanosoma evansi, and Trypanosoma vivax. Moreover, they can mechanically transmit other pathogens, such as the etiologic agents of infectious diseases like African horse sickness, anthrax, bovine anaplasmosis, bovine besnoitiosis, bovine leucosis, equine infectious anemia, lumpy skin disease, and tularemia [2-4]. In Thailand, approximately 80 species of Tabanus and their distributions have been recorded [5-7]. The most common species are T. striatus, T. megalops, and T. rubidus [5,7-9]. All three species were also reported in the epidemic area of trypanosomosis in Central Thailand [8].

The identification of Tabanus spp. employs morphological and molecular methods [5,10-14]. Morphological identification is largely based on head structures, particularly the characters of the callus, antennae, eyes, frons, and beard, together with the color and patterns of the body, legs, and wings [5]. This method is relatively simple and economical. It does not require any complicated equipment, but requires experienced taxonomists. The specimens for this method must have clear external morphological characteristics [12]. To solve morphological problems, DNA barcoding has been widely used [10-14]. This method was useful for the identification of many Tabanus spp.; it was however, unable to distinguish the members of the T. striatus complex from Thailand [12]. Tabanus striatus and T. megalops are members of the T. striatus complex, which are found in the Oriental region [5]. Based on morphological identification, T. striatus and T. megalops are distinguished by the midline of the second tergite, crossed by a stripe of pale tomentum and hairs in T. megalops, which are not present in T. striatus. In addition, the dark pattern on the abdominal dorsum of $T$. striatus is generally darker than that of T. megalops [5]. Although T. striatus and T. megalops are easily distinguished using these two characteristics, when T. megalops is stained and/or rubbed on the second tergite, it may have a $T$. striatus-like appearance [5] (Figure 1). Tabanus rubidus is distinguished from the other two species by the basal callus, which is more triangular than rectangular [5] (Figure 2). The accurate identification of these species is crucial not only to recognize the vectors involved in pathogen transmission, but for the development of appropriate control strategies. Since DNA barcoding is unable to distinguish between T. striatus and T. megalops, alternative methods, such as geometric morphometrics, have become invaluable.

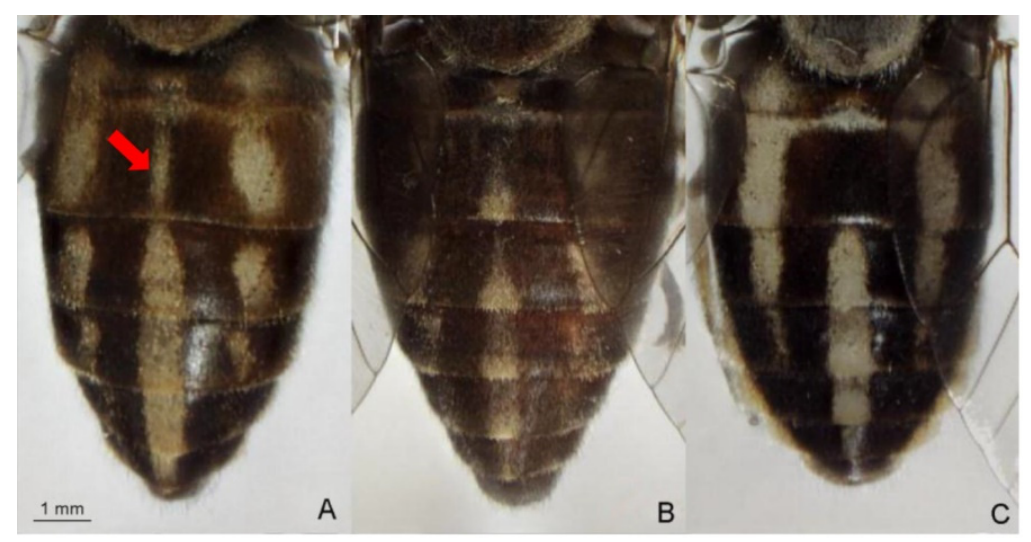

Figure 1. Morphological characteristics of abdominal dorsum used to distinguish species of Tabanus megalops (A), T. rubidus (B), and T. striatus (C). Tabanus megalops and T. striatus are distinguished by the midline of the 2 nd tergite cross by a stripe of pale tomentum and hairs in T. megalops (arrow). 


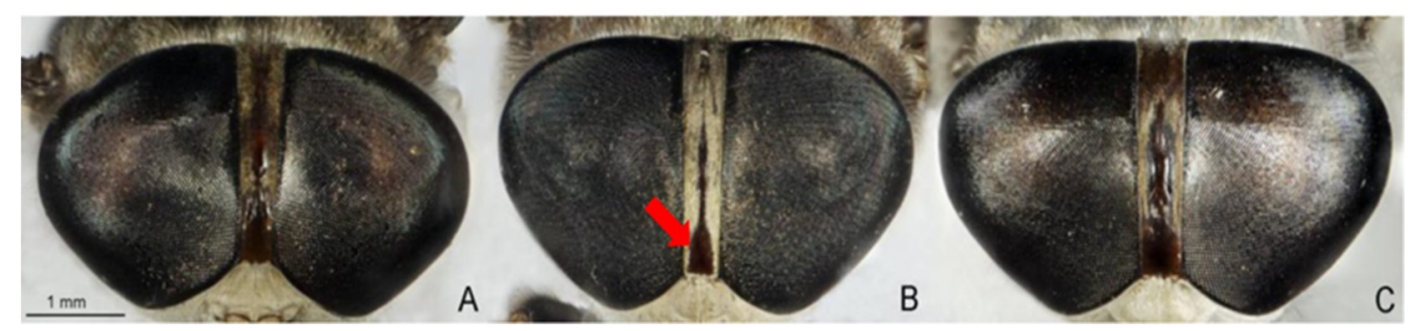

Figure 2. Morphological characteristics of basal callus used to distinguish species of Tabanus megalops (A), T. rubidus (B), and T. striatus (C). Tabanus rubidus is distinguished from T. megalops and T. striatus by the basal callus, which is more triangular than rectangular (arrow).

Wing geometric morphometrics is increasingly used for insects of medical and veterinary importance to distinguish morphologically similar species, explore intraspecific variation among populations, and determine sexual dimorphism [15-22]. The method is fast, low-cost, and easy to use [15]. Geometric morphometric analysis can be performed using various methods, such as landmark, semi-landmark, and outline-based methods, depending on the characteristics and specifics of the specimens $[15,23,24]$. The effectiveness of geometric morphometrics for species identification has been demonstrated in various models, including blow flies [20], flesh flies [25], mosquitoes [16,21,26-29], stomoxyine flies [18], sand flies [30-32], and tsetse flies [33].

In the present study, landmark-based geometric morphometrics was used to differentiate three Tabanus spp, namely, T. megalops, T. rubidus, and T. striatus, in Thailand. To generalize our results and provide an alternative method for the identification of these flies, our study material was used as reference data for the morphometric identification of additional, field collected Tabanus spp.

\section{Materials and Methods}

\subsection{Ethical Statement}

Our protocol for specimen collection was approved by the Faculty of Veterinary Science, Mahidol University Animal Care and Use Committee (Ref. MUVS-2020-01-01).

\subsection{Fly Collection and Species Determination}

Specimens of T. megalops, T. rubidus, and T. striatus were collected from different geographical regions of Thailand using five Nzi Traps [34] between February 2020 and January 2021 (Table 1, Figure 3). The traps were randomly placed at the collection sites from 06:00 to 18:00 over a two-day period. All flies were euthanized in a freezer $\left(-10^{\circ} \mathrm{C}\right)$ and placed in individual $1.5 \mathrm{~mL}$ microcentrifuge tubes. The specimens were transported to the Vector-Borne Diseases Research Unit, Faculty of Veterinary Science, Mahidol University. They were stored at $-20^{\circ} \mathrm{C}$ until morphological identification. Species recognition was performed on unambiguous specimens, i.e., those presenting clearly the specific traits or diagnostic characters, according to the descriptions and taxonomic keys of Burton (1978) [5].

A separate set of specimens (also known as unknown specimens) was collected from other geographic areas as a test of the robustness of morphometric analysis based on 410 reference wings to differentiate species. They included T. megalops (Unknown A, $\mathrm{n}=10$, from Chainat Province, Central Thailand), T. rubidus (Unknown B, $\mathrm{n}=10$, from Uthai Thani Province, Northern Thailand), and T. striatus (Unknown C, $n=10$, from Nakhon Ratchasima Province, Northeastern Thailand). Most of them had clear morphological characteristics, but some specimens of T. megalops exhibited an unclear stripe on the second tergite. 
Table 1. Collection sites and number $(\mathrm{N})$ of wing images of Tabanus spp. used for the landmark-based geometric morphometric analysis. Figures into brackets refer to sites in Figure 3.

\begin{tabular}{ccccc}
\hline Species & Regions & District/Provinces & Hosts & N \\
\hline T. megalops & Northern & Mueang, Phitsanulok (1) & Horse and buffalo \\
& Central & Mueang, Nakhon Pathom (2) & Beef cattle and buffalo & 20 \\
& & Sankhaburi, Chainat (3) & Beef cattle & $10 *$ \\
& Western & Sam Roi Yot, Prachuap Khiri Khan (4) & Beef cattle & 40 \\
& Southern & Mueang, Chumphon (5) & Beef cattle & 50 \\
T. rubidus & Northern & Mueang, Chiang Mai (6) & Beef cattle & Buffalo \\
& & Mueang, Uthai Thani (7) & Beef cattle & 40 \\
& Central & Mueang, Singburi (8) & Buffalo & 50 \\
T. striatus & Northeastern & Soeng Sang, Nakhon Ratchasima (9) & Beef cattle & Buffalo \\
& Southern & Mueang, Chumphon (5) & Buffalo & 55 \\
& Northeastern & Soeng Sang, Nakhon Ratchasima (9) & Buffalo & 30 \\
& & Wang Nam Khiao, Nakhon Ratchasima (10) & 440 \\
\hline
\end{tabular}

*, unknown specimens.

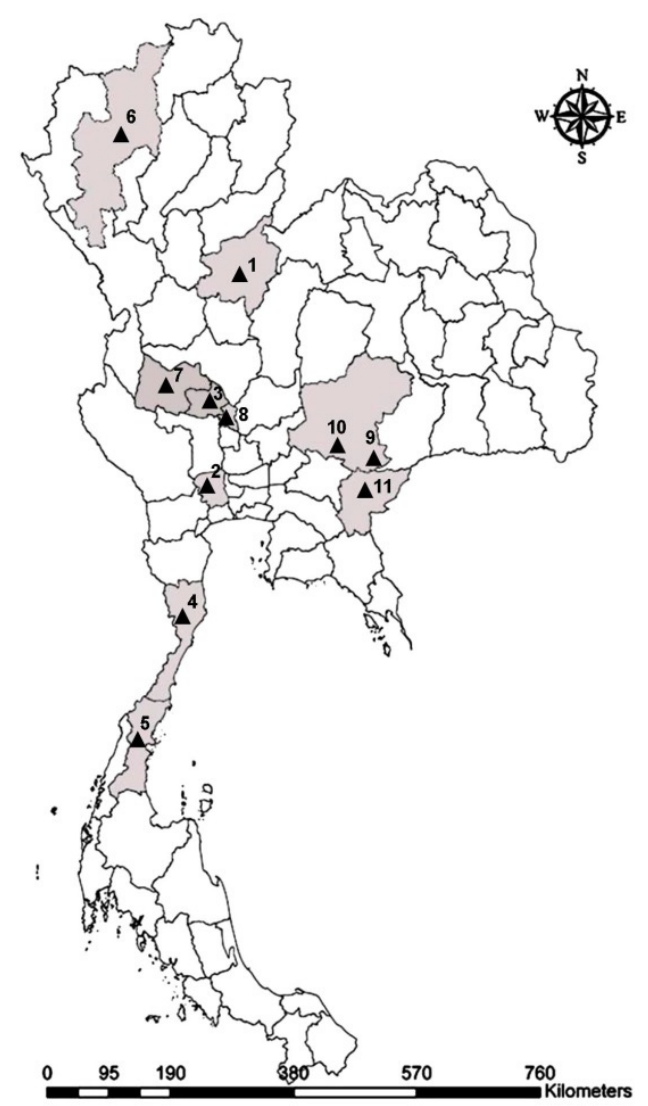

Figure 3. Map of Tabanus collection sites in Thailand: Phitsanulok (1), Nakhon Pathom (2), Chainat (3), Prachuap Khiri Khan (4), Chumphon (5), Chiang Mai (6), Uthai Thani (7), Singburi (8), Nakhon Ratchasima $(9,10)$, and Sa Kaeo (11).

\subsection{Geometric Morphometric Analysis}

\subsubsection{Wing Preparation}

The left wings of females of T. megalops, T. rubidus, and T. striatus were dissected from their bodies and carefully mounted with Hoyer's medium on microscope slides. All wing slides were photographed using a digital camera connected to a stereomicroscope (Nikon AZ 100, Nikon Corp, Tokyo, Japan) and a scale bar attached to prevent errors in the sizing of each wing. A total of 410 wing images, comprising 160 wings of T. megalops, 165 wings of 
T. rubidus, and 85 wings of $T$. striatus, were analyzed using the landmark-based geometric morphometric method (Tables 1 and S1).

\subsubsection{Inter-User Repeatability}

To check the precision of landmark digitization, a repeatability test was used for size and for shape, separately. It was computed as the ratio of the variance due to differences among individuals to the total variance [35]. The computation of the variance components of shape followed the Procrustes ANOVA method proposed by Klingenberg and Mclntyre (1998) [36]. Ten wings per species were randomly selected and digitized between two different users. If the repeatability value (of shape) was less than 0.9 , all wing pictures were re-digitized.

\subsubsection{Landmark-Based Analysis}

Coordinates of 22 wing landmarks (Figure 4) were digitized for geometric morphometric analysis. To show size variation among the groups, the global wing size was estimated using the centroid size (CS) derived from the coordinates of all landmarks. The CS is defined as the square root of the sum of the squared distances between the centroid and each landmark [37]. Statistical comparisons of the CS among the species were performed by one-way ANOVA and illustrated by quantile boxes. The statistical significance of the one-way ANOVA was estimated by a non-parametric procedure (1000 permutations) at $p$-value $<0.05$.

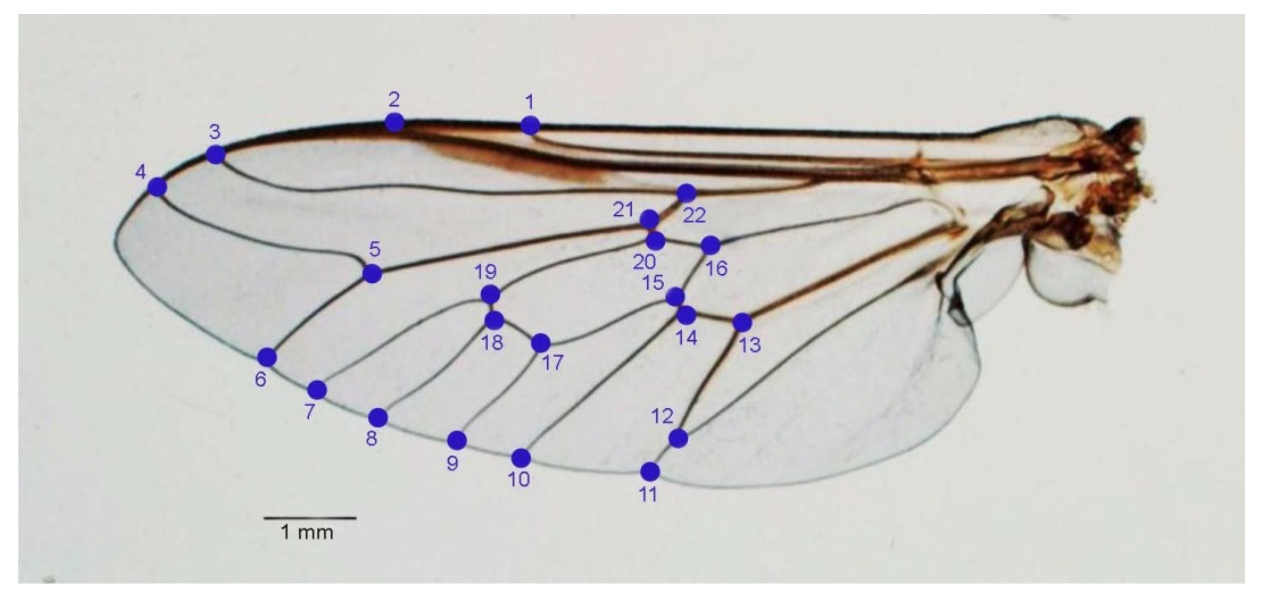

Figure 4. The twenty two landmarks digitized on the wing of Tabanus spp. for landmark-based geometric morphometric analysis.

The wing shape variables were computed after a Procrustes superimposition according to the Generalized Procrustes Analysis (GPA, see Rohlf (1990) [38]). Their principal components were used as final shape variables. The visual comparison of shape changes across species was provided by the superposition of the average wing of each species. The final wing shape variables (thus, excluding size) were used as input for discriminant analysis (DA), which were illustrated by the factor map. Statistical significance of the Mahalanobis distances among the species was estimated by a non-parametric permutation test (122 permutations) at $p$-value $<0.05$.

\subsubsection{Classification Based on Size and Shape}

To test the validity of global size (CS) for accurate species identification, we used a maximum likelihood approach [39]. To measure the taxonomic signal embedded in the shape variables, excluding size, we used a discriminant model. The latter is based on the shortest Mahalanobis distance between each specimen and the consensus shape of each species. Both classifications (size, shape) were validated classifications. Thus, each individual was sequentially removed from the total sample and assigned to the most likely 
(size) or closest (shape) group, without being used to aid the computation of the model (jack-knife classification; see Manly (2004) [40]).

\subsubsection{Allometric Effect Analysis}

The allometric effect (the effect of size on shape variation) was performed by linear regression of the first (shape derived) discriminant factor on the CS, and then estimated by the determination coefficient $r^{2}$. Thus, in our study the estimation of allometry focused on the between species shape-based discrimination.

\subsubsection{Identification of Unknown Specimens in the Field}

Our study material was used as reference data to determine 30 additional field collected specimens. These specimens came from different areas, and were used as testing specimens to be identified using the three reference groups of our study (T. megalops, T. rubidus, and T. striatus).

The identification algorithm used the shortest Mahalanobis distance of each specimen to the mean shape of each species in the same way as performed for a cross-validated classification: each unknown specimen used the discriminant space of the reference data but did not contribute to its computation [41]. Due to the necessity to recompute shape variables before each individual assignment, the repeatedly built discriminant functions are never exactly the same. This "one by one" identification process has been explained in Dujardin et al. (2010) [41] and applied in Kitthawee and Dujardin (2016) [42]. For each individual, the final species attribution was decided according to its shortest Mahalanobis distance with one of the three reference groups.

A hierarchical clustering tree (UPGMA algorithm) based on the Mahalanobis distances among the average wing shapes was used to illustrate the relationships between reference data and unknown specimens. Branch support was estimated based on 1000 bootstrap replicates of the data $[43,44]$.

\subsubsection{Morphometric Software}

Geometric and multivariate analyses were performed using XYOM (XY Online Morphometrics) version 2 software [24], freely accessible at https:/ /xyom.io/, accessed on 16 October 2021.

\section{Results}

\subsection{Inter-User Repeatability}

The two sets of measurements performed by two different users on the same images yielded high repeatability scores: $98 \%$ for size and $93 \%$ for shape.

\subsection{Wing Size Variation}

The variations in wing size (CS) among Tabanus spp. are illustrated by quantile boxes (Figure 5). The largest wings were found in T. rubidus $(13.01 \pm 0.77 \mathrm{~mm})$, followed by T. megalops $(10.01 \pm 0.67 \mathrm{~mm})$ and $T$. striatus $(10.29 \pm 0.47 \mathrm{~mm})$. Only the size of $T$. rubidus was significantly different from the two other species $(p<0.05)$. The accuracy of the maximum likelihood validated size-based classification was very high for T. rubidus $(95.76 \%)$, but less satisfactory for T. megalops $(66.25 \%)$ and T. striatus $(56.65 \%)$. 


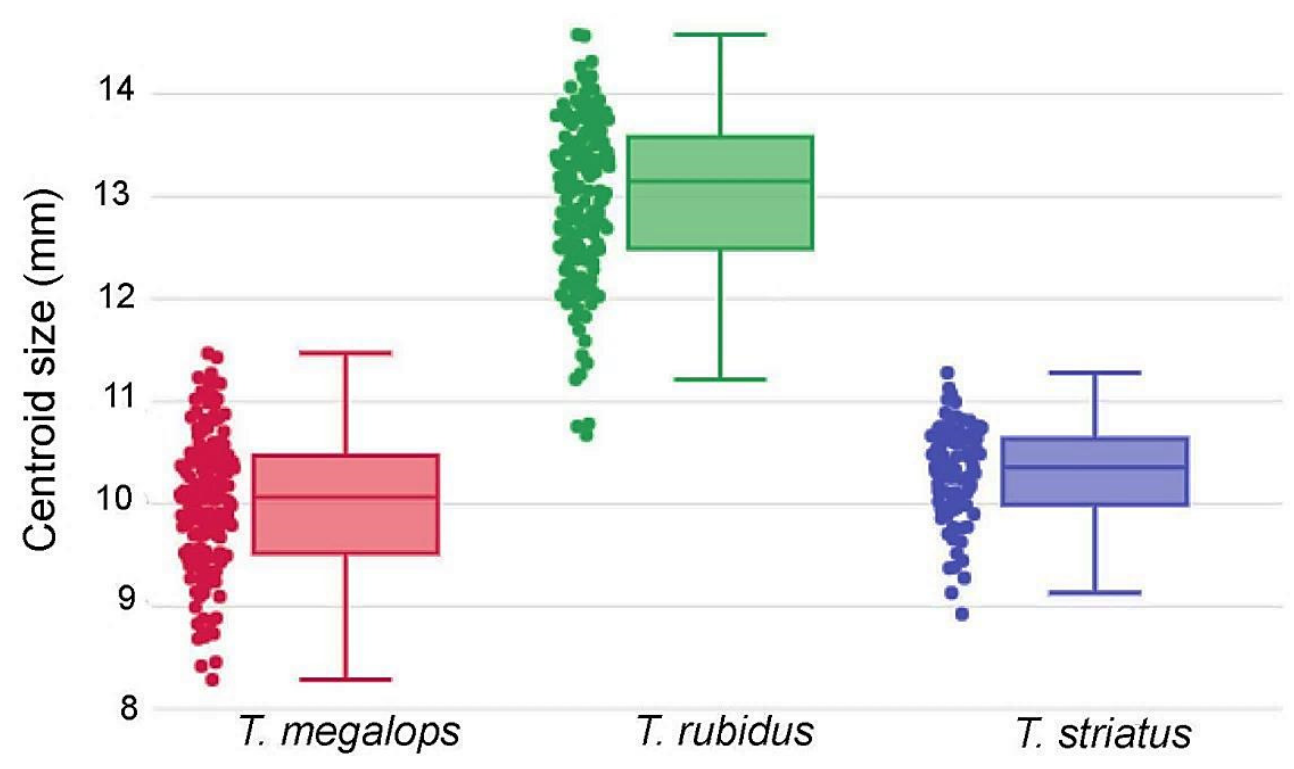

Figure 5. Quantile boxes of centroid size variations of Tabanus megalops (red, leftmost box), T. rubidus (green, central box), and T. striatus (blue, rightmost box). The horizontal line crossing each box is the median separating the 25th and 75th quartiles.

\subsection{Wing Shape Variation}

The visual comparisons of superposed configurations (Figure 6) revealed most visible landmark displacement in the anterior and middle part of the wing. The interspecific Mahalanobis distances between wing shapes were statistically significant (Table 2). The plot of the individuals on the two shape-derived discriminant factors showed T. rubidus specimens as a clear-cut external group, whereas T. megalops and T. striatus showed some overlap (Figure 7). The accuracy scores, after validated classification, were in the range of 94.38-99.39\% (Table 3).

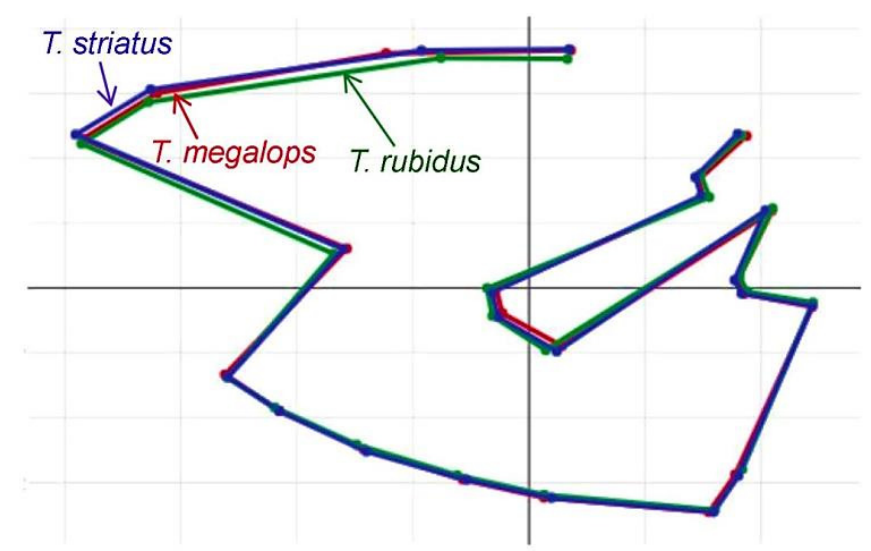

Figure 6. Mean anatomical landmark positions of Tabanus megalops (red), T. rubidus (green), and T. striatus (blue) after Procrustes superposition.

Table 2. Mahalanobis distances among the wing shapes of Tabanus megalops, T. rubidus, and T. striatus.

\begin{tabular}{cccc}
\hline Species & T. megalops & T. rubidus & T. striatus \\
\hline T. megalops & - & & \\
T. rubidus & 7.29 & - & \\
T. striatus & 4.12 & 6.19 & - \\
\hline
\end{tabular}




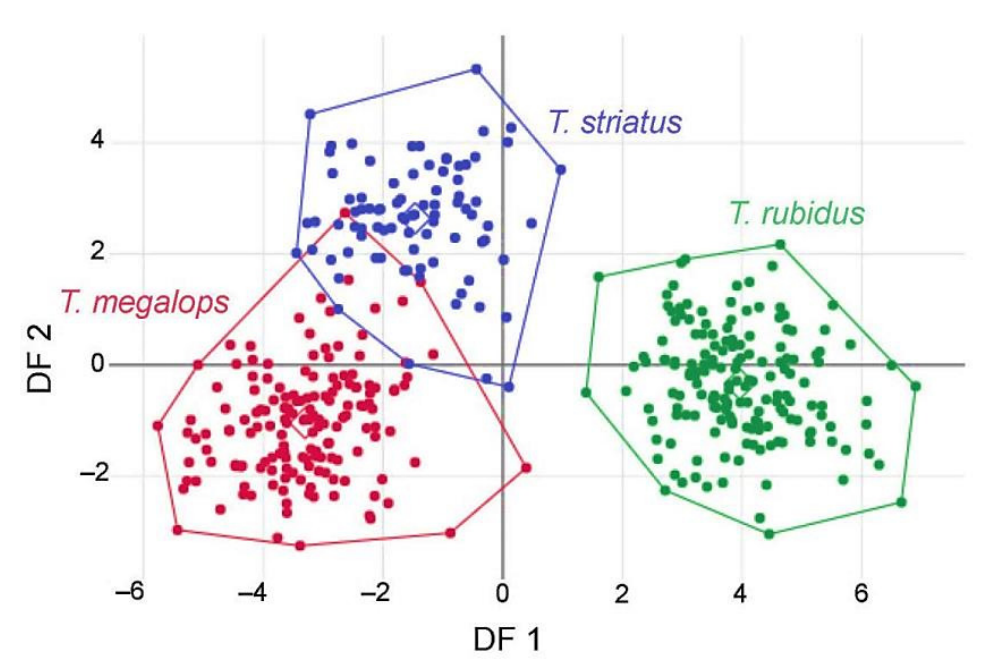

Figure 7. Factor map of the discriminant factors (DF) showing shape divergence of Tabanus megalops (red), T. rubidus (green), and T. striatus (blue). Together, the two DF represent $100 \%$ of the total discriminant space: $85 \%$ for DF1 (horizontal axis) and 15\% for DF2 (vertical axis).

Table 3. Validated classification based on the wing shapes of Tabanus megalops, T. rubidus, and T. striatus.

\begin{tabular}{cc}
\hline Species & Accuracy (Assigned/Observed) \\
\hline T. megalops & $94.38 \%(151 / 160)$ \\
T. rubidus & $99.39 \%(164 / 165)$ \\
T. striatus & $95.29 \%(81 / 85)$ \\
\hline Total performance & $96.59 \%(396 / 410)$ \\
\hline
\end{tabular}

\subsection{Allometric Effect}

The shape-based discrimination between species was significantly $(p<0.001)$ influenced by size $\left(r^{2}=43 \%\right)$ (Figure 8$)$.

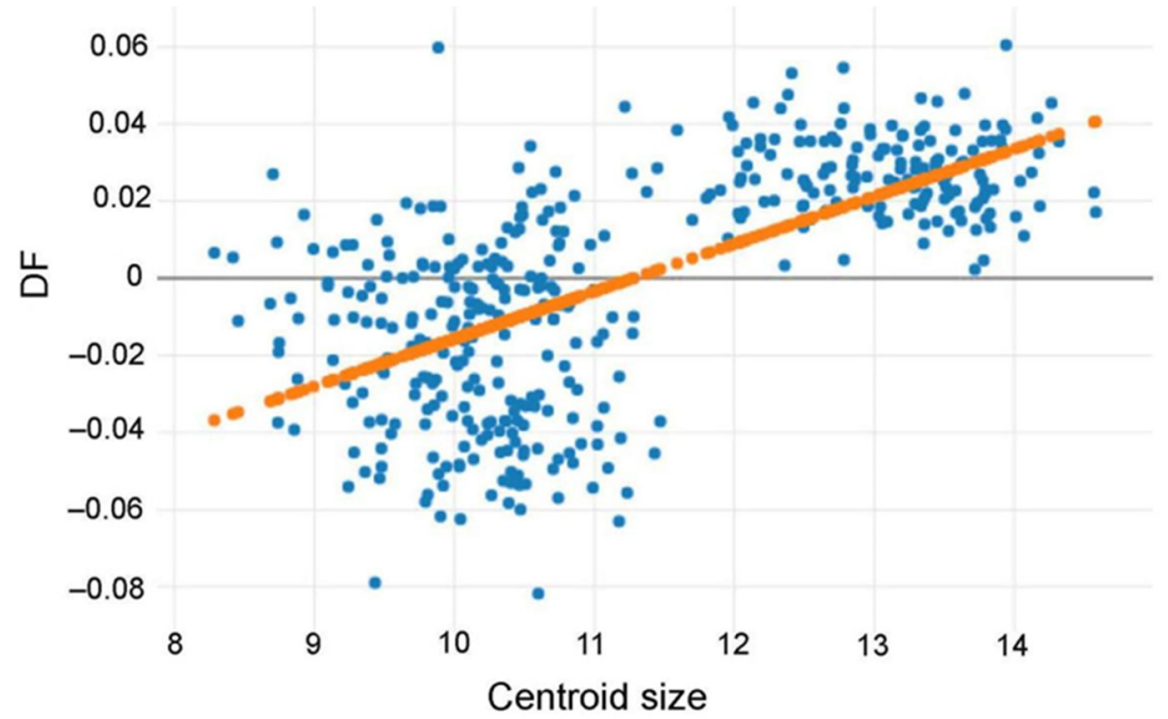

Figure 8. Linear regression prediction (orange dots line) of the first shape-based discriminant factor (DF) (vertical axis) according to the centroid size variation (horizontal axis). 


\subsection{Identification of Unknown Specimens in the Field}

The 30 field specimens were collected from other geographic areas. They were treated as "unknown" specimens to be compared to our study material, composed of T. megalops ( $\mathrm{n}=160)$, T. rubidus $(\mathrm{n}=165)$, and T. striatus $(\mathrm{n}=85)$.

The total sample classification, including reference and unknown groups, is illustrated by an UPGMA tree based on the relative Mahalanobis distances (Figure 9). This hierarchical clustering tree may be considered as an illustration of the global similarities between groups, but does not represent a true identification method.

The identification method was indeed performed individually for each unknown specimen (see the "one by one" method [41], a process which is difficult to illustrate graphically (see [42]). According to this method, the three groups corresponded to three different species, in agreement with the external morphological examination.

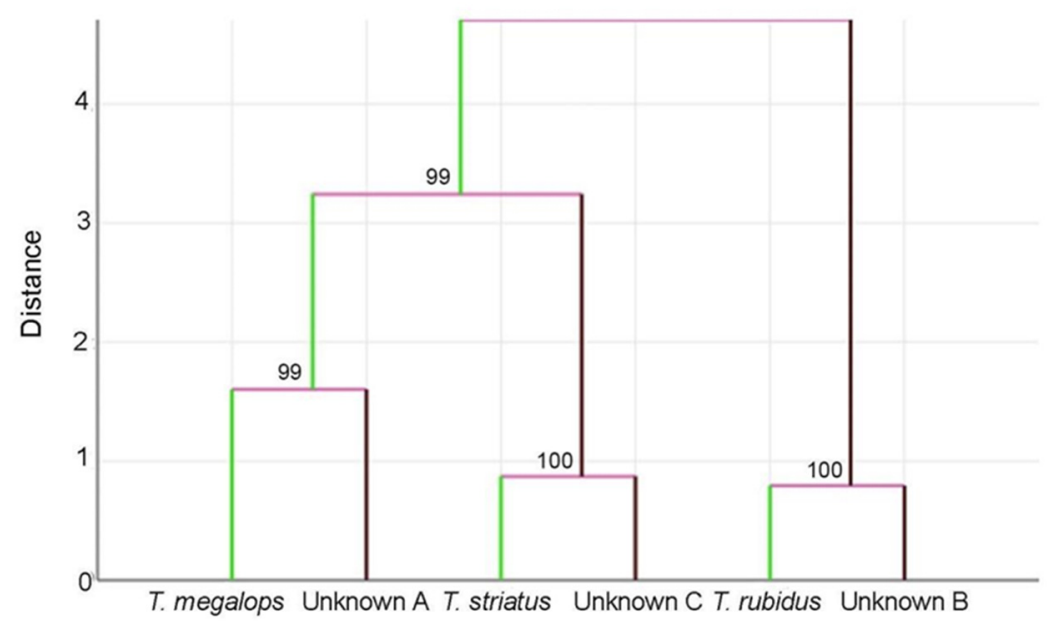

Figure 9. Hierarchical clustering tree based on shape similarities of reference data and unknown specimens. Unknown A: specimens from Chainat Province; Unknown B: specimens from Uthai Thani Province; and Unknown C: specimens from Nakhon Ratchasima Province. In this total sample classification analysis, all the specimens, including the unknown ones, helped with computing the discriminant model. The distances used for the tree construction were the Mahalanobis distances. Numbers at the nodes indicate the percentages of bootstrap values based on 1000 replicates.

\section{Discussion}

The three Tabanus spp. collected for our study have been reported as the most common species in Thailand [5,7]. Some Tabanus spp. are morphologically similar, and hence difficult to distinguish using morphological characteristics alone. Although molecular identification methods, such as DNA barcoding, were effective in separating many Tabanus spp., they were unable to distinguish members of the T. striatus complex from Thailand [12].

Our study explored an alternative method for the identification of Tabanus spp. based on the geometry of their wing venation. As the evaluation of the taxonomic power of the method was based on a non-morphometric species determination, our study material was composed of specimens unambiguously identified by morphological traits. We examined successively the size and the shape of wings as derived from the Generalized Procrustes method (GPA).

The wing size of T. megalops and T. striatus was not significantly different, but consistently smaller than that of T. rubidus: this suggested that the wing size could aid to distinguish T. rubidus from T. megalops and T. striatus. In spite of the interesting reclassifications scores based on size only, we do not recommend its use as a reliable discrimination feature. Even if reflecting genetic differences, wing size can be strongly modulated by environmental factors such as temperature, relative humidity, larval density, and food availability [45-47]. 
This is why the subsequent analyses were performed excluding size, using shape variables only. However, as shown by our allometric study (Figure 8), the discriminant space based on shape was still affected by size variation. Such influence was due mainly to the presence of a relatively large species (T. rubidus, see Figure 5), and it did not necessarily mean that shape variation was under the influence of environmental factors [15,48]. Size divergence between species is likely to be due also to evolutionary divergence [12].

The discriminant space of shape (Figure 7), the quantile boxes of size (Figure 5) and the hierarchical clustering tree of total sample analysis (Figure 9) showed that T. rubidus was clearly separated from T. megalops and T. striatus. This was in complete agreement with the known phylogenetic relationship based on cytochrome c oxidase subunit I (COI) [12]. It was also in accordance with the morphological classification: T. rubidus can be clearly distinguished from T. megalops and T. striatus, i.e., the basal callus being more triangular [5].

Tabanus megalops and T. striatus are morphologically very close species, having similar size (Figure 5) and have occasionally been misidentified, especially due to the stained or rubbed off stripe on the second tergite of T. megalops [5]. Moreover, the COI sequences did reveal between them some overlap of intraspecific and interspecific divergence [12]. Not unexpectedly, as can be visualized by their partial overlapping in the discriminant space (Figure 7), the geometry of their wing venation could not recognize them perfectly ( $94 \%$, $95 \%$, versus $99 \%$ for T. rubidus).

However, the use of the 410 images to classify images of individuals coming from other geographic locations provided satisfactory results. It gave us confidence in their possible use as a reference dataset for additional identifications, even of a single individual. The use of reference images to allow geometric morphometrics to be applied as a taxonomic tool is an old idea $[44,49,50]$. Its application can be made difficult by measurement error. When different observers digitize the same images, repeatability does not reach the level obtained when repeated measurements are performed by the same observer. This might be particularly problematic when the objective is to recognize morphologically very similar or cryptic species [43]. As an additional problem, some groups of insects may be more difficult to digitize than others. For instance, mosquitoes have wings covered by scales, hiding the precise junctions of veins. We showed that the digitization of Tabanus wings provided excellent precision, even with two different users, such that the material from our study can serve as a reference set of data for species identification.

\section{Conclusions}

The accuracy of species identification is very important for determining the role of each vector in disease transmission and for planning effective vector control and management strategies. Our study revealed that landmark-based geometric morphometrics of the wing can distinguish species within the Tabanus striatus complex (T. megalops and T. striatus) and can distinguish this group from other similar species (T. rubidus). Furthermore, our tests suggest that our study material represented a robust reference dataset able to help species determination of specimens coming from other geographic areas. The geometric method can be used as a complement to morphological identification when specimens are unclear or when there is a loss of important distinguishing characters.

Supplementary Materials: The following are available online at https: / www.mdpi.com/article / 10.3390/insects12110974/s1, Table S1: Raw coordinates of wing landmarks of Tabanus megalops (No. 1-160), T. rubidus (number 161-325) and T. striatus (number 326-410).

Author Contributions: Conceptualization, T.C. (Tanasak Changbunjong); methodology, T.C. (Tanasak Changbunjong), N.P., P.M., T.K., and T.W.; validation, T.C. (Tanasak Changbunjong) and J.-P.D.; investigation, T.C. (Tanasak Changbunjong); resources, T.C. (Tanasak Changbunjong); data curation, T.C. (Tanasak Changbunjong); writing-original draft preparation, T.C. (Tanasak Changbunjong); writing-review and editing, T.C. (Tanasak Changbunjong), T.C. (Tanawat Chaiphongpachara), and J.-P.D.; project administration, T.C. (Tanasak Changbunjong); funding acquisition, T.C. (Tanasak Changbunjong) All authors have read and agreed to the published version of the manuscript. 
Funding: This study was financially supported by the Faculty of Veterinary Science, Mahidol University (grant number 78.131/00069).

Institutional Review Board Statement: This study was approved by the Faculty of Veterinary Science, Mahidol University Animal Care and Use Committee (Ref. MUVS-2020-01-01).

Data Availability Statement: The data presented in this study are available in Supplementary Materials.

Acknowledgments: We would like to thank the authorities of the Monitoring and Surveillance Center for Zoonotic Diseases in Wildlife and Exotic Animals (MoZWE) for their kind cooperation and assistance in the study.

Conflicts of Interest: The authors declare no conflict of interest. The funders had no role in the design of the study; in the collection, analyses, or interpretation of data; in the writing of the manuscript, or in the decision to publish the results.

\section{References}

1. Morita, S.I.; Bayless, K.M.; Yeates, D.K.; Wiegmann, B.M. Molecular phylogeny of the horse flies: A framework for renewing tabanid taxonomy. Syst. Entomol. 2016, 41, 56-72. [CrossRef]

2. Stern, A.W. African horse sickness. Compend. Contin. Educ. Vet. 2011, 33, E1-E5. [PubMed]

3. Baldacchino, F.; Desquesnes, M.; Mihok, S.; Foil, L.D.; Duvallet, G.; Jittapalapong, S. Tabanids: Neglected subjects of research, but important vectors of disease agents. Infect. Genet. Evol. 2014, 28, 596-615. [CrossRef] [PubMed]

4. Mullen, B.A. Horse Flies and Deer Flies (Tabanidae). In Medical and Veterinary Entomology, 3rd ed.; Mullen, G.R., Durden, L.A., Eds.; Academic Press: London, UK, 2019; pp. 327-343.

5. Burton, J.J.S. Tabanini of Thailand above the Isthmus of Kra (Diptera: Tabanidae); Entomological Reprint Specialists: Los Angeles, CA, USA, 1978.

6. Tumrasvin, W. Tabanus species and their distribution in Thailand (Diptera: Tabanidae). Southeast Asian J. Trop. Med. Public Health 1989, 20, 319-323. [PubMed]

7. Changbunjong, T.; Sedwisi, P.; Weluwanarak, T.; Nitiyamatawat, E.; Sariwongchan, R.; Chareonviriyaphap, T. Species diversity and abundance of Tabanus spp. (Diptera: Tabanidae) in different habitats of Thailand. J. Asia. Pac. Entomol. 2018, 21, 134-139. [CrossRef]

8. Boonchit, S.; Sarataphan, N.; Tantasuvan, D. Seasonal abundance of Tabanid fly population (Diptera: Tabanidae) at a key farm, in Pathumthani province, Thailand. In Proceedings of the 34th Kasetsart University Annual Conference, Kasetsart University, Bangkok, Thailand, 30 January-3 February 1996; pp. 441-445.

9. Klinsri, T.; Leksawasdi, P. Horse fly's survey, Tabanus in Chiang Mai Province. In Proceedings of the 37th Kasetsart University annual conference, Kasetsart University, Bangkok, Thailand, 3-5 February 1999; pp. 39-46.

10. Cywinska, A.; Hannan, M.A.; Kevan, P.G.; Roughley, R.E.; Iranpour, M.; Hunter, F.F. Evaluation of DNA barcoding and identification of new haplomorphs in Canadian deerflies and horseflies. Med. Vet. Entomol. 2010, 24, 382-410. [CrossRef]

11. Banerjee, D.; Kumar, V.; Maity, A.; Ghosh, B.; Tyagi, K.; Singha, D.; Kundu, S.; Laskar, B.A.; Naskar, A.; Rath, S. Identification through DNA barcoding of Tabanidae (Diptera) vectors of surra disease in India. Acta Trop. 2015, 150, 52-58. [CrossRef]

12. Changbunjong, T.; Bhusri, B.; Sedwisai, P.; Weluwanarak, T.; Nitiyamatawat, E.; Chareonviriyaphap, T.; Ruangsittichai, J. Species identification of horse flies (Diptera: Tabanidae) in Thailand using DNA barcoding. Vet. Parasitol. 2018, 259, 35-43. [CrossRef]

13. Mugasa, C.M.; Villinger, J.; Gitau, J.; Ndungu, N.; Ciosi, M.; Masiga, D. Morphological re-description and molecular identification of Tabanidae (Diptera) in East Africa. ZooKeys 2018, 769, 117-144. [CrossRef]

14. Votýpka, J.; Brzoňová, J.; Ježek, J.; Modrý, D. Horse flies (Diptera: Tabanidae) of three west African countries: A faunistic update, barcoding analysis and trypanosome occurrence. Acta Trop. 2019, 197, 105069. [CrossRef]

15. Dujardin, J.P. Morphometrics applied to medical entomology. Infect. Genet. Evol. 2008, 8, 875-890. [CrossRef]

16. Ruangsittichai, J.; Apiwathnasorn, C.; Dujardin, J.P. Interspecific and sexual shape variation in the filariasis vectors Mansonia dives and Ma. bonneae. Infect. Genet. Evol. 2011, 11, 2089-2094. [CrossRef] [PubMed]

17. Gómez, G.F.; Márquez, E.J.; Gutiérrez, L.A.; Conn, J.E.; Correa, M.M. Geometric morphometric analysis of Colombian Anopheles albimanus (Diptera: Culicidae) reveals significant effect of environmental factors on wing traits and presence of a metapopulation. Acta Trop. 2014, 135, 75-85. [CrossRef]

18. Changbunjong, T.; Sumruayphol, S.; Weluwanarak, T.; Ruangsittichai, J.; Dujardin, J.P. Landmark and outline-based geometric morphometrics analysis of three Stomoxys flies (Diptera: Muscidae). Folia Parasitol. 2016, 63, 37. [CrossRef]

19. Lorenz, C.; Almeida, F.; Almeida-Lopes, F.; Louise, C.; Pereira, S.N.; Petersen, V.; Vidal, P.O.; Virginio, F.; Suesdek, L. Geometric morphometrics in mosquitoes: What has been measured? Infect. Genet. Evol. 2017, 54, 205-215. [CrossRef] [PubMed]

20. Sontigun, N.; Sukontason, K.L.; Zajac, B.K.; Zehner, R.; Sukontason, K.; Wannasan, A.; Amendt, J. Wing morphometrics as a tool in species identification of forensically important blow flies of Thailand. Parasit. Vectors 2017, 10, 229. [CrossRef] 
21. Chaiphongpachara, T.; Sriwichai, P.; Samung, Y.; Ruangsittichai, J.; Vargas, R.E.M.; Cui, L.; Sattabongkot, J.; Dujardin, J.P.; Sumruayphol, S. Geometric morphometrics approach towards discrimination of three member species of Maculatus group in Thailand. Acta Trop. 2019, 192, 66-74. [CrossRef] [PubMed]

22. Changbunjong, T.; Ruangsittichai, J.; Duvallet, G.; Pont, A.C. Molecular Identification and Geometric Morphometric Analysis of Haematobosca aberrans (Diptera: Muscidae). Insects 2020, 11, 451. [CrossRef] [PubMed]

23. Dujardin, J.P.; Kaba, D.; Solano, P.; Dupraz, M.; McCoy, K.D.; Jaramillo-O, N. Outline-based morphometrics, an overlooked method in arthropod studies? Infect. Genet. Evol. 2014, 28, 704-714. [CrossRef] [PubMed]

24. Dujardin, S.; Dujardin, J.P. Geometric morphometrics in the cloud. Infect. Genet. Evol. 2019, 70, 189-196. [CrossRef] [PubMed]

25. Sontigun, N.; Samerjai, C.; Sukontason, K.; Wannasan, A.; Amendt, J.; Tomberlin, J.K.; Sukontason, K.L. Wing morphometric analysis of forensically important flesh flies (Diptera: Sarcophagidae) in Thailand. Acta Trop. 2019, 190, 312-319. [CrossRef]

26. Lorenz, C.; Marques, T.C.; Sallum, M.A.; Suesdek, L. Morphometrical diagnosis of the malaria vectors Anopheles cruzii, An. homunculus and An. bellator. Parasit. Vectors 2012, 5, 257. [CrossRef]

27. Sumruayphol, S.; Apiwathnasorn, C.; Ruangsittichai, J.; Sriwichai, P.; Attrapadung, S.; Samung, Y.; Dujardin, J.P. DNA barcoding and wing morphometrics to distinguish three Aedes vectors in Thailand. Acta Trop. 2016, 159, 1-10. [CrossRef]

28. Gómez, G.F.; Correa, M.M. Discrimination of Neotropical Anopheles species based on molecular and wing geometric morphometric traits. Infect. Genet. Evol. 2017, 54, 379-386. [CrossRef]

29. Martinet, J.-P.; Ferté, H.; Sientzoff, P.; Krupa, E.; Mathieu, B.; Depaquit, J. Wing Morphometrics of Aedes Mosquitoes from North-Eastern France. Insects 2021, 12, 341. [CrossRef] [PubMed]

30. Dujardin, J.P.; Le Pont, F.; Baylac, M. Geographical versus interspecific differentiation of sand flies (Diptera: Psychodidae): A landmark data analysis. Bull. Entomol. Res. 2003, 93, 87-90. [CrossRef]

31. Giordani, B.F.; Andrade, A.J.; Galati, E.A.B.; Gurgel-Gonçalves, R. The role of wing geometric morphometrics in the identification of sandflies within the subgenus Lutzomyia. Med. Vet. Entomol. 2017, 31, 373-380. [CrossRef] [PubMed]

32. Godoy, R.E.; Shimabukuro, P.H.F.; Dos Santos, T.V.; Pessoa, F.A.C.; Da Cunha, A.E.F.L.; Santos, F.K.M.; Vilela, M.L.; Rangel, E.F.; Galati, E.A.B. Geometric morphometry of the head in sand flies (Diptera: Psychodidae: Phlebotominae), an alternative approach to taxonomy studies. Zootaxa 2018, 26, 566-576. [CrossRef]

33. Kaba, D.; Berté, D.; Ta, B.T.; Tellería, J.; Solano, P.; Dujardin, J.P. The wing venation patterns to identify single tsetse flies. Infect. Genet. Evol. 2017, 47, 132-139. [CrossRef]

34. Mihok, S. The development of a multipurpose trap (the Nzi) for tsetse and other biting flies. Bull. Entomol. Res. 2002, 92, 385-403. [CrossRef]

35. Arnqvist, G.; Martensson, T. Measurement error in geometric morphometrics: Empirical strategies to assess and reduce its impact on measures of shape. Acta Zool. Academ. Sci. Hung 1998, 44, 73-96.

36. Klingenberg, C.P.; McIntyre, G.S. Geometric morphometrics of developmental instability: Analyzing patterns of fluctuating asymmetry with Procrustes methods. Evolution 1998, 52, 1363-1375. [CrossRef] [PubMed]

37. Bookstein, F.L. Morphometric Tools for Landmark Data. Geometry and Biology; Cambridge University Press: Cambridge, UK, 1991.

38. Rohlf, F.J. Rotational fit (Procrustes) methods. In Proceedings of the Michigan Morphometrics Workshop; University of Michigan Museum of Zoology: Ann Arbor, MI, USA, 1990; pp. 227-236.

39. Dujardin, J.P.; Dujardin, S.; Kaba, D.; Santillán-Guayasamín, S.; Villacís, A.G.; Piyaselakul, S.; Sumruayphol, S.; Samung, Y.; Morales-Vargas, R. The maximum likelihood identifcation method applied to insect morphometric data. Zool. Syst. 2017, 42, $46-58$.

40. Manly, B.F.J. Multivariate Statistical Methods: A Primer; Chapman Hall/CRC Press: Boca Raton, FL, USA, 2004.

41. Dujardin, J.P.; Kaba, D.; Henry, A.B. The exchangeability of shape. BMC Res. Notes 2010, 22, 266. [CrossRef] [PubMed]

42. Kitthawee, S.; Dujardin, J.P. The Diachasmimorpha longicaudata complex in Thailand discriminated by its wing venation. Zoomorphology 2016, 135, 323-332. [CrossRef]

43. Couette, S.; Escarguel, G.; Montuire, S. Constructing, bootstrapping, and comparing morphometric and phylogenetic trees: A case study on new world monkeys (Platyrrhini, Primates). J. Mammal. 2005, 85, 773-781. [CrossRef]

44. Morales Vargas, R.E.; Phumala-Morales, N.; Tsunoda, T.; Apiwathnasorn, C.; Dujardin, J.P. The phenetic structure of Aedes albopictus. Infect. Genet. Evol. 2013, 13, 242-251. [CrossRef]

45. Jirakanjanakit, N.; Leemingsawat, S.; Thongrungkiat, S.; Apiwathnasorn, C.; Singhaniyom, S.; Bellec, C.; Dujardin, J.P. Influence of larval density or food variation on the geometry of the wing of Aedes (Stegomyia) aegypti. Trop. Med. Int. Health 2007, 12, 1354-1360. [CrossRef]

46. Morales Vargas, R.E.; Ya-umphan, P.; Phumala-Morales, N.; Komalamisra, N.; Dujardin, J.P. Climate associated size and shape changes in Aedes aegypti (Diptera: Culicidae) populations from Thailand. Infect. Genet. Evol. 2010, 10, 580-585. [CrossRef]

47. Phanitchat, T.; Apiwathnasorn, C.; Sungvornyothin, S.; Samung, Y.; Dujardin, S.; Dujardin, J.P.; Sumruayphol, S. Geometric morphometric analysis of the effect of temperature on wing size and shape in Aedes albopictus. Med. Vet. Entomol. 2019, 33, 476-484. [CrossRef]

48. Horenstein, M.B.; Peretti, A.V. Environmental conditions influence allometric patterns in the blow fly, Chrysomya albiceps. J. Insect Sci. 2011, 11, 131. [CrossRef] [PubMed] 
49. Yang, H.P.; Ma, C.S.; Wen, H.; Zhan, Q.B.; Wang, X.L. A tool for developing an automatic insect identification system based on wing outlines. Sci. Rep. 2015, 5, 12786. [CrossRef] [PubMed]

50. Robinson, C.; Terhune, C.E. Error in geometric morphometric data collection: Combining data from multiple sources. Am. J. Phys. Anthropol. 2017, 164, 62-75. [CrossRef] [PubMed] 